\title{
Versatilidad del colgajo dorsal en cirugía de reconstrucción de sarcoma de pared torácica. Reporte de caso
}

\author{
Versatility of the dorsal flap in reconstruction surgery of toracica wall \\ sarcoma. Case report
}

Mauro Porto Varela1, Mariana Pane Núñez², Rodrigo Frachi ${ }^{3}$ Derliz Mussi ${ }^{3}$, Osvaldo Aquino ${ }^{4}$

\section{RESUMEN}

Entre los tumores malignos de la pared torácica, los sarcomas representan menos del $1 \%$ de los casos. A pesar de ser infrecuentes, es importante resaltar el manejo multidisciplinario de estos tipos de tumores ya que se caracterizan por ser de gran tamaño y afectar una amplia superficie torácica y por consiguiente de los tejidos blandos anexos a los mismos. De ahí la real importancia de la participación de cirujanos plásticos, torácicos y oncólogos en el tratamiento de estos tumores. La confección del colgajo dorsal en cirugías de sarcomas de la pared torácica ha permitido completar el tratamiento resectivo de dichos tumores.

Presentamos el caso de un paciente varón de 64 años, con un sarcoma de la parrilla costal, quien fue sometido a resección amplia de la lesión que comprometia a la $7 \mathrm{ma}, 8 \mathrm{va}$ y 9 na costillas, reconstrucción inmediata con próstesis de titanio y malla de polipropileno y cobertura del defecto con confección de colgajo del dorsal ancho. A 5 meses de seguimiento, sin evidencia de actividad de la enfermedad

Palabras claves: colgajo, reconstrucción, sarcomas.

\begin{abstract}
Among malignant tumors of the chest wall, sarcomas account for less than $1 \%$ of cases. Despite being infrequent, it is important to highlight the multidisciplinary management of these types of tumors since they are characterized by being large and affecting a wide chest area and therefore the soft tissues attached to them. Hence the real importance of the participation of pásticos, thoracic and oncologos surgeons in the treatment of these tumors. The confection of the dorsal flap in surgeries of sarcomas of the thoracic wall has allowed to complete the treatment of these tumors.

We present the case of a 64-year-old male patient with a sarcoma of the rib cage, who underwent extensive resection of the lesion involving the 7th, 8th and 9th ribs, immediate reconstruction with titanium prosthesis and mesh. polypropylene and coverage of the defect with flap made of the latissimus dorsi. At 5 months of follow-up, without evidence of disease activity.
\end{abstract}

Key words: flap, reconstruction, sarcomas.

REVISTA ARGENTINA DE CIRUGÍA PLÁSTICA 2019;25(2):77-79. HTTPS://DOI.ORG/10.32825/RACP/201902/0077-0079

\section{INTRODUCCIÓN}

Los sarcomas de partes blandas representan un grupo infrecuente de neoplasias que derivan del tejido mesenquimatoso con una frecuencia que no alcanza el $1 \%$ del total de tumores malignos.

Los sarcomas que se presentan a nivel de la pared torácica son un grupo más infrecuente aún, que pueden derivar de tejidos blandos, óseos o cartilaginosos. Se ha observado una mayor frecuencia de sarcomas provenientes de huesos o cartilagos, representando más del $50 \%$ del total, y son menos frecuentes los se originan en tejidos blandos y muscular.

1. Residente de primer año

2. Residente de segundo año

3. Médico de planta

4. Jefe de Servicio de Cirugía Plástica, Reconstructiva y Quemados. Instituto de Previsión Social, Hospital Central, Asunción, Paraguay

$\square$ Correspondencia: Dr. Mauro Porto Varela: Residente de primer año. Cirugía Plástica Reconstructiva y Quemados IPS. portovama@ gmail.com

Los autores no declaran conflictos de intereses

Recibido: 29/08/2019 / Aceptado: 30/08/2019
Inequívocamente el tratamiento de estos tumores es la resección quirúrgica, con la reconstrucción correspondiente del defecto que dejan estos tumores por la gran superficie que frecuentemente ocupan en la pared torácica.

Al ser la pared torácica una estructura con cierta rigidez con una superficie de tejidos blandos adaptada a dicha rigidez, cualquier compromiso torácico por tumores u otra situación compromete también a los tejidos que la cubren. Esto lleva al desafío de la reconstrucción de los defectos en la pared torácica, en donde el cierre de aproximación "borde a borde" no es posible, por lo cual se deben diseñar estrategias que permiten recubrir los defectos. Por tanto, la reconstrucción de la pared torácica supone un desafío desde el punto de vista reconstructivo en el que es fundamental el papel de los cirujanos plásticos, sobre todo cuando se trata de reparar grandes defectos con el fin de obtener una reparación funcional y anatómica correctas.

\section{MATERIALES Y MÉTODOS}

Se realizó revisión de la ficha clínica y operatoria de un paciente de sexo masculino operado en el mes de marzo del año 2019 en el Servicio de Cirugía Plástica Reconstructiva y Quemados del Instituto de Previsión Social, Hospital Central. 


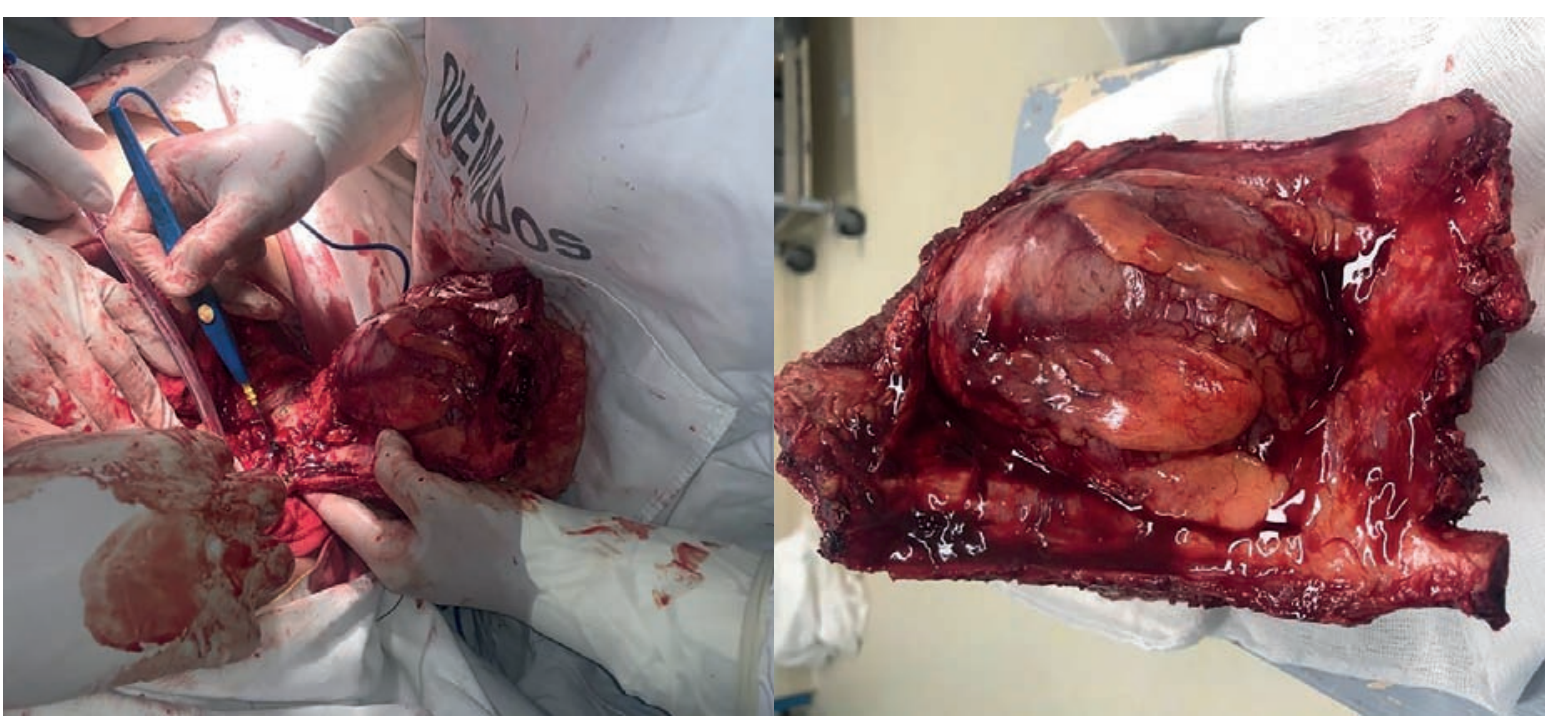

Figuras 1 y 2. Fotografía de la pieza de resección quirúrgica compuesta por sarcoma de la parrilla torácica y los arcos costales anteriores.

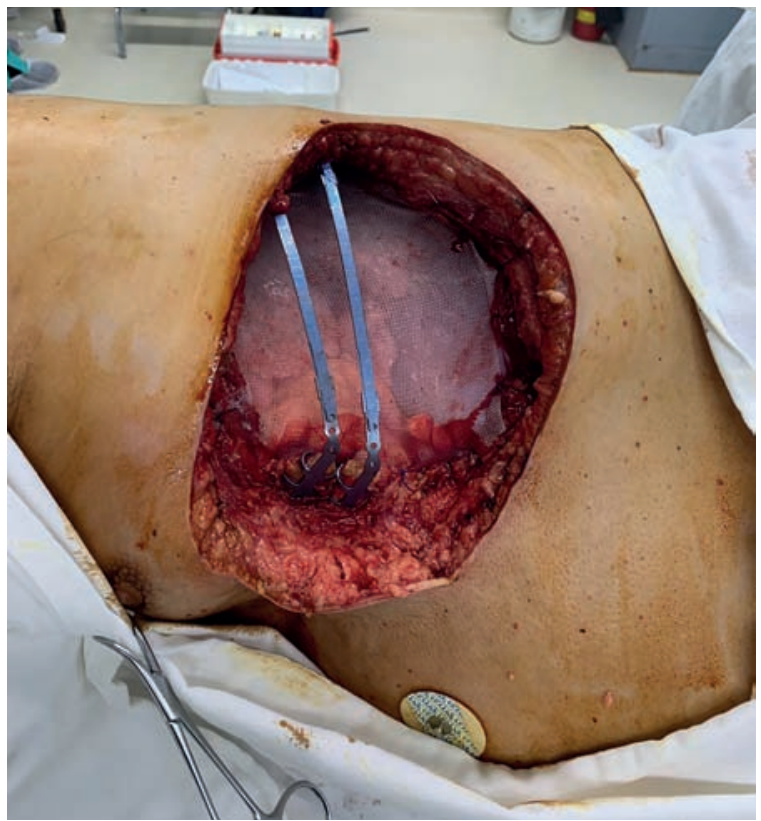

Figura 3. Reconstrucción con prótesis de titanio y malla de polipropileno.

\section{CASO CLINICO}

Varón de 64 años, sin antecedentes de importancia, referido a cirugía de tórax por presentar aumento de volumen en la pared del tórax, que afecta al hemitórax izquierdo. La lesión es indolora en un inicio, un mes previo a su valoración presenta dolor asociado que incrementa con el esfuerzo y disminuye con el reposo, refiere además pérdida de peso de aproximadamente $3 \mathrm{Kg}$ desde hace 6 meses; sin otro síntoma acompañante.

Clínicamente, presenta un tumor en la cara anterior del tórax de $10 \mathrm{~cm}$ de diámetro, sobre la línea medioclavicular a nivel de la novena costilla, firmemente adherido a la parrilla costal.
La radiografía simple de tórax muestra una opacidad en la mitad media e inferior del hemitórax izquierdo con afección de tejidos blandos extrapulmonares; los arcos costales, el parénquima y la silueta cardíaca son normales.

Una tomografía computarizada de tórax revela una masa lobulada, de bordes bien definidos, con dimensiones de $1010 \times 8 \mathrm{~cm}$ de diámetro en la parte anterior del hemitórax izquierdo, que parece infiltrar músculos intercostales y tejido celular subcutáneo, sin producir infiltración aparente al parénquima pulmonar que presenta refuerzo heterogéneo tras la administración de constraste. La punción guiada por ecografía informa la presencia de un sarcoma, por lo que se decide cirugía resectiva de la lesión. Se propone resección amplia de parrilla costal y reconstrucción con prótesis de titanio, malla de polipropileno y colgajo dorsal.

Es sometido a toracotomía izquierda y resección en bloque de tumor de parrilla torácica (Figuras 1 y 2). Resección de séptimo, octavo y noveno arcos costales anteriores izquierdos. Reconstrucción inmediata con prótesis de titanio y malla de polipropileno (Figura 3). Se procede a la recosntrucción con colgajo del dorsal ancho (Figuras 4 y 5 ).

La evolución posoperatoria del paciente es satisfactoria, es trasladado en el posoperatorio inmediato la unidad de cuidados intensivos y en el décimo día posoperatorio, a sala comun. Se realiza control estricto del colgajo dorsal no evidenciándose congestión, palidez o sufrimiento del mismo (Figura 6).

El reporte histopatológico definitivo demuestra un sarcoma de partes blandas de alto grado histológico, identificando 3 arcos costales con longitud de $9 \mathrm{~mm}$ y 1,3 $\mathrm{cm}$ de diámetro, que estaban atrapadas por el tumor pero no infiltrados. El tumor llega a tener contacto con la pleura parietal.

Una tomografía de control a los 4 meses después de fi- 


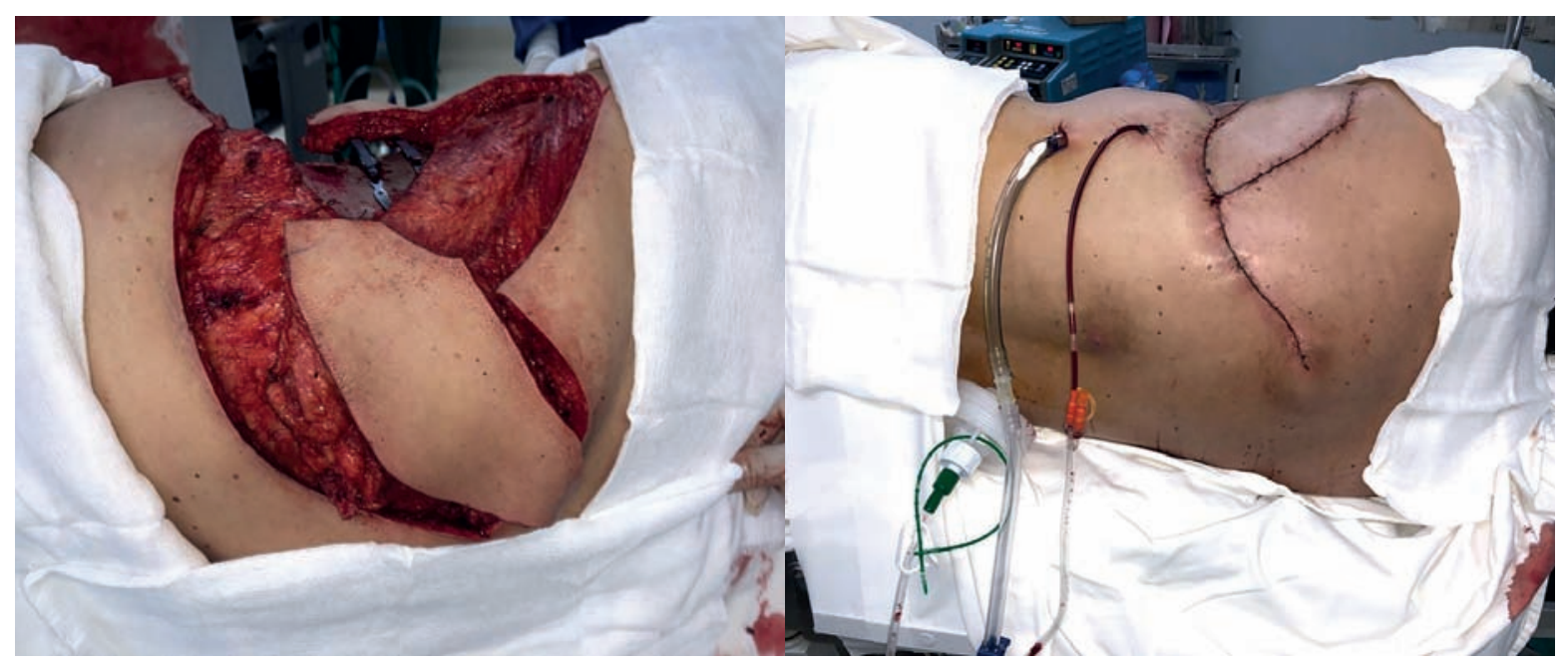

Figuras 4 y 5. Imagen intraoperatoria de la reconstrucción de la parrilla torácica, con colgajo del dorsal ancho.

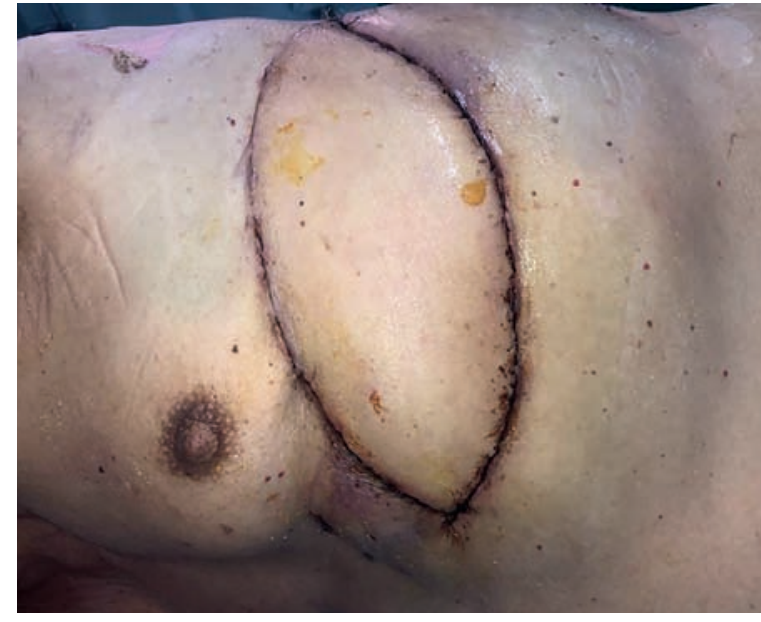

Figura 6. Colgajo del dorsal ancho. nalizado el tratamiento, evidencia la presencia de la prótesis de titanio, además de cambios posquirúrgicos.

\section{CONCLUSIÓN}

Los sarcomas de la parrilla costal son neoplasias infrecuentes que tienden a afectar gran superficie torácica, por lo que el tratamiento multidisciplinario de dichos tumores es de fundamental importancia.

El colgajo dorsal ha demostrado su versatilidad en las más variadas cirugías resectivas, lo que permite realizar reconstrucciones como la realizada en el caso presentado, en el que una importante superfice de tejidos blandos se vio afectada. Esta técnica, además de permitir la cobertura de grandes defectos de la pared, se acompaña de bajas tasas de morbilidad en pacientes seleccionados.

\section{BIBLIOGRAFÍA}

1. Cancer Statics, 2014. CA Cancer J Clin 2014;64(1):9-29.

2. Losken A, VH. Thourani VH, Carlson GW et al.: "A reconstruc- tivealgorithm for plastic surgery following extensive chest wall resection". Br J Plast Surg 2004:57: 295.

3. Arnold PG, Pairolero PC.: "Chest-wall reconstruction: an account of 500 consecutive patients". Plast Reconstr Surg 1996; 98: 804.

4. Cohen M, Ramasastry SS.: "Reconstruction of complex chest wall defects".Am J Surg 1996; 172:35.

5. Skoracki RJ, Chang DW.: "Reconstruction of the chest wall and thorax". J Surg Oncol 2006;94:455.

6. Primary chest wall tumors. J Am Coll Surg 2010;210(3):360-366

7. Management of truncal sarcoma. En: Malawer MM, Sugarbaker PH (editors). Musculoskeletal Cancer Surgery: Treatment of Sarcomas and Allied Diseases. The Netherlands: Kluwer Academic Publishers; 2001. p. 165-177.

8. Review of chest wall tumors: A diagnostic, therapeutic, and reconstructive challenge. Semin Plast Surg 2011;25(1):16-24.

9. Primary chest wall tumors. Thorac Surg Clin 2010;20(4):495-507.
10. Chest wall tumors: radiologic findings and pathologic correlation: part 2. Malignant tumors. Radiographics 2003; 23:1491-508.

11. Prediction of Treatment Outcomes in Patients with Chest Wall Sarcoma: Evaluation with PET/CT. JPn J Clin Oncol 2012;42(10):912-918.

12. Soft tissue sarcomas of the trunk wall (STS-TW): a study of 343 patients from the French Sarcoma Group (FSG) database. Ann Oncol 2009;20(6):1127-1135.

13. Outcome after surgical resections of recurrent chest wall sarcomas. J Clin Oncol 2008;26(31):5113-5118.

14. Reconstruction of the chest wall and thorax. J Surg Oncol 2006:94(6):455-465.

15. Chest wall resections and reconstruction: a 25-year experience. Ann Thorac Surg 2002;73(6):1720-1725.

16. Malignant primary chest-wall tumours: techniques of reconstruction and survival. Eur J Cardiothorac Surg 2010;38(1):39-45.

17. Consequences of varicella and herpes zoster in pregnancy: Prospective study of 1739 cases. Eur J Cardiothorac Surg 2001; 19:589-93 